which the Porritt Committee sought to translate into practice through its area hospital board scheme must be achieved in some other way. It should not be impossible to create unifying administrative authorities at some such level as that envisaged for the Area Health Boards, leaving the regional boards as they are and perhaps enlarging their scope, and their constitution, to hold a watching, co-ordinating brief over the activities of the smaller areas. Such an arrangement would make sense in the future pattern of medical services such as can be seen to be emerging and in which the present demarcation lines between general, hospital, and public health practice will be less marked.

The Minister and the Ministry of Health should now get together with the medical profession to see how the paths indicated by the Porritt Committee may be profitably followed. A refreshing spirit of adventure is in the air. Those in authority should not be afraid to experiment.

\section{FOOD IN HOSPITALS}

"Remember that sick cookery should half do the work of your poor patient's weak digestion," wrote Florence Nightingale in 1859 in her Notes on Nursing, and modern research has confirmed the importance of good feeding in the care of the sick. It is therefore disturbing to learn from a report published this week ${ }^{1}$ that the standards of feeding in many National Health Service hospitals are lamentably low.

This important study by Professor B. S. Platt and two lecturers in his Department of Human Nutrition arose out of a small investigation by Platt and his colleagues in seven hospitals in West Cornwall at the request of the West Cornwall Hospital Management Committee, which must be given credit for seeking facts rather than relying on opinion. This investigation showed that there was excessive waste of food in hospitals and that about half the meals did not reach adequate nutritional standards. The results were so disquieting that the Nuffield Provincial Hospitals Trust made a grant of $£ 30,000$ for a scientific study of hospital food on a scale large enough to be representative of England and Wales. Platt and his colleagues therefore picked at random 152 hospitals for study ; they included hospitals of various sizes for the reception of acute, chronic, and mental cases. In each hospital the diet of one patient was sampled and evaluated over 24 hours, and observations were made on how the food was prepared, served, and disposed of.

The first conclusion reached by Platt and his colleagues deserves special emphasis at a time when bigger and better hospitals are being planned, for they report \footnotetext{
2 Platt, B. S., Ediy, T. P., and Pellett. P. L., Food in Hospitals. Nuffield
Provincial Hospital Trust (Oxford University Press), 1963. 21s. net.
}

that " the larger the hospital the lower was the efficiency of administration and the quality of food as served." The greatest attention to the patient's needs was found in small hospitals, mostly those with 60 beds or fewer. Yet it is ironic to reflect that it is precisely this type of hospital which is due to be abolished and replaced by large district hospitals.

The cooking and serving of foods comes in for serious criticism: "There was a tendency to overcook vegetables, and there were long delays in the service of meals. In half the largest hospitals, it took more than an hour and a half to cook and serve potatoes to patients. Occasionally the service of meals to patients was delayed by ward rounds or faulty administration. These defects in preparation and service damaged the food, causing nearly complete loss of vitamin $C$ in potatoes and $75 \%$ loss in green vegetables." The authors comment on lack of variety and poor quality of food in large hospitals for acute cases, while the quality of meals in long-stay hospitals for the chronic sick was "extremely poor." The average intakes of vitamin $\mathrm{C}$ and iron are considered to be barely adequate in some hospitals and " at the worst, in chronic hospitals, inadequate and liable to cause anaemia." Perhaps not surprisingly in view of its poor quality the waste of food from the meals sent to the wards was found to be excessive, amounting to $40-45 \%$, chiefly in the form of food left in the serving dishes. Waste was greater in large hospitals (except in mental hospitals) than in small hospitals.

Serious defects in the standards of cleanliness and hygiene were frequent, especially in ward kitchens, where the low standards in handling food often formed a remarkable contrast with the zealous aseptic ritual of the main part of the ward. For instance, in one hospital a "temporary ward" in a group of huts put up after the war was examined. It was " very well kept," and special attention was devoted to keeping it clean. Yet the ward kitchen was "very cramped, not well cared for, and dirty." Enamelled aluminum trays were used but the enamel had worn off. "The floor was dirty, the trolley was dirty," and a vacuum cleaner was lying in a dirty cardboard carton under the kitchen table, while flex from the hot-food trolley trailed over the table. Indeed, the description of this place, as of some of the others visited, is reminiscent of Dickens's Dotheboys Hall.

As would be expected from a team of distinguished nutritionists the remedies they propose exemplify the principles of sound nutrition. Among other things they emphasize that all the patients' diets, and not only special therapeutic diets, are a matter for medical concern. Dietitians should pay more attention to everyday problems of catering, and the status of catering officers should be raised, they suggest. One person in every hospital should be responsible for catering, though at ward level feeding must be the responsibility of the ward sister. 
In some hospitals a new category of auxiliary might with advantage be appointed - the ward caterer. These and other proposals that Platt and his colleagues make are clearly acceptable or worthy of serious study. But it may be questioned whether other measures ought not to receive equally urgent attention. The practical problems are immense and not all in the field of nutrition. Consequently there may be a case for further study by a team broadened by the inclusion of one or more experienced men from the catering industry. Perhaps the Nuffield Provincial Hospitals Trust would consider sponsoring a piece of operational research which would be the natural corollary to the study they have already supported. Meanwhile Platt and his colleagues have produced an arresting report.

\section{WHICH CONTRACEPTIVE?}

In response to requests from its members, the Consumers' Association has investigated currently available contraceptives, with the exception of "the pill," for which a prescription is needed. The object was to give " test results, broad comparisons and best buys in contraceptives-just like any other subject." The findings are published this month as a Supplement to Which ${ }^{1}$

Investigation was thorough and it comes as no surprise to learn that the Which? shoppers and laboratory testers were on this job for eighteen months. Eight hundred samples of each of the 27 most widely marketed brands of condom were tested for leakage, strength, size, and weight, 300 of the samples being obtained after the London Rubber Industries, makers of the eight most frequently encountered brands, had announced a major improvement in quality. Fifty samples of each of seven brands of washable sheath, six brands of diaphragm (dutch caps), and nine brands of other types of cap (four cervical, three vault, and two "other") were tested before and after accelerated ageing. Washable sheaths were tested for holes, strength, and size, and diaphragms, in addition, for the resilience of their encircling springs. Tests on the condoms, washable sheaths, and diaphragms were based on those in draft British Standards, but in the absence of one for caps their testing was based on a method used by the Family Planning Association. Some less familiar rubber appliances were also studied.

In addition to laboratory testing, information on price, presence or absence of instructions and name of manufacturer, packaging, and advertising claims was collected.

Chemical contraceptives were also examined. Forty-one brands of creams, jellies, and pastes were tested for spermicidal activity by an elaboration of the International Planned Parenthood Federation's test for " total spermicidal nower." Their constituents-when stated-were reviewed for "harmlessness" in the light of evidence from the Family Planning Association, the I.P.P.F., and the manu-

Contraceptives: Which? Supplement, November 15, 1963. Available only to members of the Consumers' Association, 14 Bucikingham Street, London to members of the Consumers facturers. A check was made to see that they did not damage rubber. Fifty brands of suppository, 16 brands of foaming tablet, and one aerosol foam were tested. Again details of manufacturer (if stated), price, instructions, and advertising were assembled. To complete the survey a calculator for the "safe period" and two brands of ovulation thermometer were studied.

"From our test results," says the Consumers' Association, "it is clear that the user of contraceptives can easily be paying too much and be getting an unreliable product." With condoms, the most popular type of contraceptive, of which about $100,000,000$ are said to be sold yearly in the United Kingdom, the failure rate to a simple leakage test with $300 \mathrm{ml}$. of water was on average $3-4 \%$ with the best brands and over $12 \%$ in the worst. "No brand," comments C.A., "would have passed the present draft British Standard which is aimed at accepting brands with a failure rate of 1 per cent." It is pointed out that in the U.S.A. much higher manufacturing standards prevail. Over there, states the report, "all the brands we tested would be in danger of seizure by the U.S. Food and Drug Administration." Prices of condoms ranged from $3 \frac{1}{2} \mathrm{~d}$. to $3 \mathrm{~s}$. $4 \mathrm{~d}$. each, and these wide differences, it seems, were "in no way related to their freedom from defects." With no brand was the date of manufacture given, and usually the package did not provide instructions on use or storage, nor the name of the manufacturer or distributor. Some of the brand advertising is condemned, particularly when in the guise of disinterested advice in family planning.

Of the 41 chemical spermicides, 24 brands passed the sperm-killing test. But not all of them indicated what they contained and it was therefore only possible to say that 13 of the 24 had been shown to be harmless. The C.A. is disturbed by this lack of information and recommends legislation to bring all chemical contraceptives within the definition of medicines, to enforce declaration of their ingredients.

The value of the Which? Supplement is enhanced by chapters on the physiology of conception, methods of contraception (including the safe period) and their choico, how to find a clinic (there is a list of family planning clinics in the United Kingdom), buying contraceptives, and on how to achieve conception. There is also a short note about oral contraceptives, and there are excellent illustrations. The F.P.A. and the I.P.P.F. are thanked specifically for their "help and encouragement" in preparing the report. The Consumers' Association is to be congratulated on its enterprise.

\section{ADDICTION TO CHLORODYNE}

The side-effects and complications of new drugs receive increasing attention. The importance of also keeping older remedies under review is illustrated by Dr. M. F. Conlon's paper published recently in this journal ${ }^{1}$ reporting three cases of addiction to chlorodyne. This preparation, tincture of chloroform and morphine, is a traditional ingredient of cough mixtures and intestinal sedatives, among them three mixtures included in the British National Formulary. It is also a homely (and palatable)

1 Conlon, M. F., Brit. med. J., 1963, 2, 1177. 